\title{
Thermal conductivity measurement and prediction of particulate foods
}

\author{
James K. Carson*
}

School of Engineering, University of Waikato, Private Bag 3105, Hamilton 3240, New Zealand

*corresponding author: j.carson@waikato.ac.nz

\begin{abstract}
There is reason to question some of the published thermal conductivity data for particulate foods. It is argued in this paper, based on thermal conductivity bounds analysis, that the thermal conductivity of particulate foods should range between $0.03 \mathrm{~W} \mathrm{~m}^{-1} \mathrm{~K}^{-1}$ and $0.30 \mathrm{~W} \mathrm{~m}^{-1} \mathrm{~K}^{-1}$, (provided the porosity is greater than $25 \%$ ) and that any data outside this range should be rejected. This argument was supported by data for five foods measured as part of this study (cocoa powder, corn starch, whole milk powder, sucrose and wheat flour), and the majority of published data for particulate foods do indeed fall within this range. The Geometric model was found to provide the most accurate thermal conductivity predictions of the models considered, and is recommended for use in first approximation predictions.
\end{abstract}

Keywords: thermal conductivity, powdered food, particulates

\section{Nomenclature}

$\begin{array}{ll}F & \text { intermediate variable defined by Eq. (13) } \\ G & \text { intermediate variable defined by Eq. (14) } \\ k & \text { thermal conductivity }\left(\mathrm{W} \mathrm{m}^{-1} \mathrm{~K}^{-1}\right) \\ m & \text { mass (kg) } \\ Q & \text { heater power }\left(\mathrm{W} \mathrm{m}^{-1}\right) \\ t & \text { time (s) } \\ T & \text { temperature }\left({ }^{\circ} \mathrm{C} \text { or } \mathrm{K}\right)\end{array}$


porosity (i.e. volume fraction of air)

$\xi$ absolute model prediction error $\left(\mathrm{W} \mathrm{m}^{-1} \mathrm{~K}^{-1}\right)$

$\rho$ density $\left(\mathrm{kg} \mathrm{m}^{-3}\right)$

Subscripts

$a$

property of air

c

property of condensed phase

$e$

$i$

w

effective property

component index

property or water

\section{INTRODUCTION}

Thermal conductivity is an important parameter for modelling thermal processes including cooking, drying, sterilisation, pasteurisation, chilling and freezing. Such models allow for process optimisation to improve quality and efficiency ${ }^{[1-3]}$. A significant number of thermal conductivity data for minimally processed foods may be found in the literature ${ }^{[1,3-7]}$; however, there can be significant variation in published data for a given food product ${ }^{[8]}$, and it is often difficult to analyse the data since one or more relevant factors such as the food's composition, the measurement temperature or measurement technique are not always stated within the article. This is particularly relevant for particulate foods, where the bulk density or porosity is often not reported $^{[4-6]}$. 
As an example, consider thermal conductivity data for wheat 'flour' ${ }^{[5,17]}$ compared to wheat 'dust ${ }^{\text {'[5,19] }}$. The names of these two products would suggest that they would be morphologically similar (i.e. fine particles/powder), and yet their thermal conductivities differ by an order of magnitude $\left(0.67 \mathrm{~W} \mathrm{~m}^{-1} \mathrm{~K}^{-1}\right.$ compared to $\left.0.06 \mathrm{~W} \mathrm{~m}^{-1} \mathrm{~K}^{-1}\right)$. The measurements from the two sources were performed at different temperatures and had different moisture contents, but even accounting for these factors could not explain the difference. Similarly, data for soy-flour ${ }^{[4,5]}$ range from $0.04 \mathrm{~W} \mathrm{~m}^{-1} \mathrm{~K}^{-1}$, to $0.95 \mathrm{~W} \mathrm{~m}^{-1} \mathrm{~K}^{-1}$; the latter of which is very high for any (unfrozen) food product, being significantly higher than the thermal conductivity of water between 0 and $100{ }^{\circ} \mathrm{C}^{[1]}$. At the opposite extreme, data for whole rapeseed ${ }^{[20]}$ (as cited by Wallapapan et al. ${ }^{[21]}$ ) was as low as $0.0009 \mathrm{~W} \mathrm{~m}^{-1} \mathrm{~K}^{-1}$ which is orders of magnitude of thin air itself $\left(0.025 \mathrm{~W} \mathrm{~m}^{-1} \mathrm{~K}^{-1}\right.$ at $\left.25{ }^{\circ} \mathrm{C}^{[1]}\right)$.

Given that particulate foods contain significant (i.e. greater than $25 \%$ ) porosity (where 'porosity' refers to any void volume within the food), tend to be relatively dry (i.e. have low moisture content), and tend to have carbohydrates as the dominant nutritional component, from theory one would expect a narrower thermal conductivity range in the published data than is currently observable. It was not the aim of this paper to critique all the published data for particulate foods individually (since some may simply be typographical errors); instead the aim of this paper was to consider what ranges of thermal conductivities of powdered foods should be expected from theoretical considerations and to describe how simple effective thermal conductivity models can be used to moderate (i.e. check for plausibility) existing data, and as a check before new measurements are published.

\section{THEORETICAL CONSIDERATIONS}

The thermal conductivity of a heterogeneous material (such as a food product) is theoretically bounded by the Parallel (Eq. 1) and Series (Eq. 2) thermal conductivity models, often referred to as the 'Wiener bounds' ${ }^{\text {'[9]: }}$ 
Parallel:

$$
k_{e}=\sum_{i} k_{i} v_{i}
$$

Series:

$$
k_{e}=\frac{1}{\sum_{i} \frac{v_{i}}{k_{i}}}
$$

where $k$ is thermal conductivity and $v$ is volume fraction of the food component. The thermal conductivity of a food should not exceed the thermal conductivity predicted by Eq. (1) or be below that predicted by Eq. (2), provided the food components' thermal conductivities and relative amounts are known accurately.

Now consider two hypothetical foods: the first is bone dry carbohydrate and has a porosity of 0.82 (about the upper limit of porosity found in the literature for a particulate food); the second hypothetical food has a porosity of 0.25 (the lower limit of porosity for particulates) and has a condensed phase which is $40 \%$ water and $60 \%$ carbohydrate (wet basis). Since the first hypothetical food is low in moisture content and high in porosity, we would expect it to have a thermal conductivity close to the lowest possible value for a particulate material. Conversely, since the second hypothetical food has low porosity and high moisture content we would expect it to have a thermal conductivity close to the highest possible value for particulate foods.

The upper and lower thermal conductivities for each food, as predicted by the Parallel and Series models (based on food component thermal conductivities at $20{ }^{\circ} \mathrm{C}$ ) are $0.30 \mathrm{~W} \mathrm{~m}^{-1} \mathrm{~K}^{-1}$ and 0.03 $\mathrm{W} \mathrm{m}{ }^{-1} \mathrm{~K}^{-1}$ respectively. The lowest predicted thermal conductivity is for the first hypothetical food (i.e. the lower bound for the hypothetical food expected to have lowest thermal conductivity) and the highest is for the second hypothetical food (upper bound for the hypothetical food expected to have the highest thermal conductivity).

The Wiener bounds apply to materials having any structure; however for isotropic materials (including the randomly arranged particulate foods), the Hashin Shtrikman bounds apply, which lie within the Wiener bounds ${ }^{[10,11]}$. For a particulate food, the lower Hashin-Shtrikman bound is 
equivalent to the Maxwell-Eucken model with air as the continuous phase (Eq. 3) and the upper bound is equivalent to the Maxwell-Eucken model with air as the dispersed phase (Eq. 4):

Maxwell-Eucken (air continuous) ${ }^{[10-12]}: k_{e}=k_{a} \frac{2 k_{a}+k_{c}-2\left(k_{a}-k_{c}\right)(1-\varepsilon)}{2 k_{a}+k_{c}+\left(k_{a}-k_{c}\right)(1-\varepsilon)}$

Maxwell-Eucken (air dispersed) ${ }^{[10-12]:} \quad k_{e}=k_{c} \frac{2 k_{c}+k_{a}-2\left(k_{c}-k_{a}\right) \varepsilon}{2 k_{c}+k_{a}+\left(k_{c}-k_{a}\right) \varepsilon}$

where the subscript $a$ refers to air, the subscript $c$ refers to the condensed phase (i.e. liquid/solid phase) and $\varepsilon$ is the porosity (i.e. the volume fraction of air). Applying the upper HashinShtrikman bound (Eq. 4) to the hypothetical foods, the predicted thermal conductivity is $0.27 \mathrm{~W}$ $\mathrm{m}^{-1} \mathrm{~K}^{-1}$, while the lower bound (Eq. 3) is $0.04 \mathrm{~W} \mathrm{~m}^{-1} \mathrm{~K}^{-1}$.

For particulate foods, which may be classed as 'external porosity' materials, even narrower bounds have been proposed ${ }^{[11,12]}$ where the effective medium theory model (Eq. 5) serves as the upper bound and Eq. (3) serves as the lower bound:

Effective Medium Theory (EMT) ${ }^{[13]:} \quad \sum_{i} v_{i} \frac{k_{e}-k_{i}}{2 k_{i}+k_{e}}=0$

Applying the upper external porosity bound (Eq. 5) to the hypothetical foods, the predicted thermal conductivity is only $0.18 \mathrm{~W} \mathrm{~m}^{-1} \mathrm{~K}^{-1}$ (the lower bound is the same as the lower HashinShtrikman bound, i.e. $0.04 \mathrm{~W} \mathrm{~m}^{-1} \mathrm{~K}^{-1}$ ). It is difficult, therefore, to conceive how measured data for powdered foods can be accurate if is significantly higher than $0.3 \mathrm{~W} \mathrm{~m}^{-1} \mathrm{~K}^{-1}$, or lower than $0.03 \mathrm{~W} \mathrm{~m}^{-1} \mathrm{~K}^{-1}$. While there is inherent variability in the thermal properties of biological materials such as foods, and there is also inherent variability between different measurements from the same measurement device applied to the same food ${ }^{[14]}$, these factors on their own cannot explain the wide range of thermal conductivity values that have been published for particulate foods ${ }^{[1,4-6]}$. Conversely, the majority of the published data do in fact lie between $0.04 \mathrm{~W} \mathrm{~m}^{-1} \mathrm{~K}^{-1}$ and $0.2 \mathrm{~W} \mathrm{~m}^{-1} \mathrm{~K}^{-1}$ which corresponds to the range predicted by the external porosity bounds. 


\section{MATERIALS AND METHOD}

While there is a large number of thermal conductivity data for particulate foods within the literature, relatively few of them are presented with supporting information that would be required to test the thermal conductivity models without making some assumptions. Therefore, in order to test these thermal conductivity bounds without introducing bias from different measurement apparatus and measurement techniques (as might be the case if data from the limited amount that is suitable for the purpose were to be used), the thermal conductivities of five powdered foods were measured at $20{ }^{\circ} \mathrm{C}$ specifically for this study, along with the composition measurements required for the application of Eqs. (1) to (5).

\section{Thermal Conductivity Measurement}

A Hukseflux ${ }^{\mathrm{TM}}$ TP08 thermal conductivity probe was used for the thermal conductivity measurement. Its design complies with ASTM D 5334-00, D 5930-97 and IEEE 442-1981 standards ${ }^{[15]}$. The probe needle was $70 \mathrm{~mm}$ long and $1.2 \mathrm{~mm}$ in diameter. The sample powders were poured into a watertight, stainless-steel sample container (constructed as per recommendations in the TP08 user manual ${ }^{[15]}$ ) and shaken and tapped several times until the powder had settled. The sample containers were placed in a Julabo ${ }^{\mathrm{TM}}$ FP40 temperaturecontrolled bath. Measurements were performed with baseline temperatures of $20^{\circ} \mathrm{C}$. The thermal conductivity probe was inserted into the sample which was allowed to equilibrate at the base-line temperature. Once the sample had equilibrated the heater was switched on and the probe temperature was recorded. After a period of time ( $2-4$ minutes) the heater was switched off and the sample was allowed to return to the base-line temperature before a replicate measurement was performed. Once the value of the slope of the linear portion of the curve has been determined, the thermal conductivity of the sample may be calculated from Eq. $(6)^{[16]}$ : 


$$
k=\frac{Q \ln \left(t_{2} / t_{1}\right)}{4 \pi\left(\Delta T_{2}-\Delta T_{1}\right)}
$$

$Q$ is the heater power $\left(\mathrm{W} \mathrm{m}^{-1}\right), t_{1}$ and $t_{2}$ are two different times (s) during the linear portion of the $\Delta T$ vs. $\ln t$ curve, and $\Delta T_{1}$ and $\Delta T_{2}(\mathrm{~K})$ correspond to the differences between the probe and the base-line temperatures at times $t_{1}$ and $t_{2}$ respectively.

\section{Bulk density and moisture content measurements}

In order to compare the measured data against thermal conductivity model predictions, bulk densities and moisture contents were also measured. Bulk densities were measured using volumetric flasks, and the standard deviation between replicates was used as an estimate of the measurement uncertainty. The moisture contents of each sample was measured by drying the sample at $105^{\circ} \mathrm{C}$ until the mass became steady with time, in which case the moisture content was determined from:

$$
x_{w}=\frac{m_{\text {initial }}-m_{\text {final }}}{m_{\text {initial }}}
$$

Porosity may be calculated from bulk density via the following relationship:

$$
\varepsilon=\frac{\rho_{c}-\rho_{e}}{\rho_{c}-\rho_{a}}
$$

where the density of the condensed phase $\left(\rho_{c}\right)$ may be calculated from the component densities and volume fractions:

$$
\rho_{c}=\sum_{i} v_{i} \rho_{i}
$$

or, alternatively, from mass fractions:

$$
\rho_{c}=\frac{1}{\sum_{i} \frac{x_{i}}{\rho_{i}}}
$$


where the densities of the major food components $\left(\rho_{\mathrm{i}}\right)$ may be obtained from the literature ${ }^{[1]}$

\section{Materials}

Five particulate foods were considered in these experiments: corn starch, sucrose, wheat flour, cocoa powder and milk powder (all were in powder form, i.e. with mean particle diameters less than $0.1 \mathrm{~mm}$ ). All were standard commercial products purchased from a local store. Where applicable, the protein, fat and carbohydrate mass percentages as specified by the manufacturer are shown in Table 1.

\section{RESULTS AND DISCUSSION}

Table 2 shows the measured moisture contents, apparent densities and thermal conductivities of the five powders. The thermal conductivity data in Table 2 are the averages of at least 15 measurements performed on at least three different samples, and the standard deviation of the measurements ranged between 1 and $2.5 \%$ of the mean value. The probe manufacturer stated that the uncertainty in a typical measurement is $\pm 3 \%{ }^{[15]}$, and since this value is greater than the standard deviation, it is used as the error estimate for the measurements. The uncertainty in the bulk density and moisture content measurements is estimated to be less than $1 \%$.

Comparison between measured data and published data is complicated by the differences in moisture contents, bulk densities and measurement temperatures (or, in the case of cocoa powder, corn-starch powder and sucrose powder, lack of published data). However, the data for wheat flour are comparable to data (for wheat 'dust') measured by Chang et al. ${ }^{[19]}$, the milk powder measurement is similar to data measured using a guarded hot-plate by MacCarthy ${ }^{[4,18]}$.

\section{Comparison of measured data against thermal conductivity bounds}


Table 3 shows the measured thermal conductivity against the Weiner, Hashin Shtrikman and External Porosity bounds. Note that Eqs. (3) and (4) are for binary mixtures, and so for multicomponent foods the models must should applied sequentially, adding an extra component at each step. However, for simplicity the thermal conductivities of the non-gaseous food components have been modelled by Eq. (1) to produce the conductivity of the condensed phase $\left(k_{c}\right)$ for subsequent use in Eqs. (3) and (4). The justification for this approach has been provided elsewhere ${ }^{[8,22]}$. Although Eq. (5) can be applied for multi-component mixtures, the sequential approach (i.e. Eq. 1 for non-gaseous foods to produce $k_{c}$, followed by Eq. 5) was applied for simplicity of implementation.

Table 3 shows that for each of the five foods the measured thermal conductivity lies within the external porosity bounds, allowing for measurement uncertainty (the error bar of milk powder overlaps the bound), which means that they also necessarily fall within the Hashin-Shtrikman and Wiener bounds. Figures 1 to 3 illustrate this graphically (note that each data point has been plotted separately, since the food compositions, and hence $k_{c}$, are different for each food). The measured data support the theory that the thermal conductivity of particulate foods should lie within bounds. Although testing five different foods at one temperature cannot be considered a complete validation of the theory, a much greater number of measured data in the literature ${ }^{[1,4-6]}$ would fall within the Wieners bounds at least (as far as can be inferred from the data which is supplied with the thermal conductivity measurements themselves). Hence the thermal conductivity bounds may serve two valuable purposes:

1. They may be used as a check on measured data (provided the porosity is greater than $25 \%$ ) - at the very least those data which lie outside the Wiener bounds should be rejected. This would hopefully reduce the number of clear outliers amongst the data which are published.

2. For particulate foods the external porosity bounds, being much narrower than the Wiener bounds, allow for the prediction of the limits of thermal conductivity for a given particulate food. 


\section{Thermal conductivity prediction for powdered foods}

It is also worthwhile considering whether a thermal conductivity model can predict the actual thermal conductivity of these particulate foods, rather than simply upper and lower bounds of thermal conductivity. For genuine predictions, models that do not contain parameters whose values must be determined empirically are preferable. We expect the thermal conductivities of particulate foods to lie within the region bounded by Eqs. (4) and (5) (i.e. the external porosity bounds ${ }^{[11]}$ ), Three models that meet these criteria ${ }^{[8,11,12]}$ (no empirical parameters, predicted thermal conductivity falling within the external porosity region) are the Geometric, Levy ${ }^{[23]}$ and Co-continuous ${ }^{[24]}$ models:

Geometric:

$$
k_{e}=\prod_{i} k_{i}^{v_{i}}
$$

$\operatorname{Levy}^{[23]}$ :

$$
\begin{gathered}
k_{e}=k_{a} \frac{2 k_{a}+k_{c}-2\left(k_{a}-k_{c}\right) F}{2 k_{a}+k_{c}+\left(k_{a}-k_{c}\right) F} \\
F=\frac{2 / G-1+2(1-\varepsilon)-\sqrt{[2 / G-1+2(1-\varepsilon)]^{2}-8(1-\varepsilon) / G}}{2}
\end{gathered}
$$

Co-continuous (CC) model $^{[24]}$ :

$$
G=\frac{\left(k_{c}-k_{a}\right)^{2}}{\left(k_{c}+k_{a}\right)^{2}+k_{c} k_{a} / 2}
$$$$
k_{e}=\frac{\sum_{i} \frac{v_{i}}{k_{i}}}{2}\left(\sqrt{1+\frac{8 \sum_{i} k_{i} v_{i}}{\sum_{i} \frac{v_{i}}{k_{i}}}}-1\right)
$$

Table 4 presents the thermal conductivities of Eqs. (11), (12) and (15) against the measured thermal conductivity data and the absolute prediction error of the models, as defined by:

$$
\xi=\left|k_{\text {model }}-k_{\text {measured }}\right|
$$


Table 4 shows that of the six models the Geometric model (Eq. 11) provides the most accurate predictions, which is perhaps unsurprising, since it divides the external porosity region most evenly (see Figure 5 of Carson ${ }^{[8]}$ ). It is therefore recommended for general use for obtaining first approximation estimates of the thermal conductivity of particulate foods.

\section{CONCLUSION}

Theoretical arguments suggest that the thermal conductivity of particulate foods should fall within the range $0.03 \mathrm{~W} \mathrm{~m}^{-1} \mathrm{~K}^{-1}$ and $0.2 \mathrm{~W} \mathrm{~m}^{-1} \mathrm{~K}^{-1}$ (provided the porosity is greater than $25 \%$ ). This was found to be the case when the thermal conductivities of five different particulate foods were measured. The majority of published thermal conductivity data for particulate foods also falls within this range. It is therefore suggested that whenever the thermal conductivity of a particulate food is measured, the measured value should be compared to the values predicted by the Series and Parallel models at the very least, and if it is higher than the value predicted by the Parallel model, or lower than the value predicted by the Series model, it should be rejected. Of the different thermal conductivity models considered, the Geometric model provided the most accurate predictions.

\section{REFERENCES}

1. ASHRAE Handbook of Refrigeration, American Society of Heating, Refrigeration and Air-conditioning Engineers, Atlanta GA, 2006

2. Fellows, P J., Food processing technology - principles and practice $2^{\text {nd }}$ Ed., Woodhead Publishing Ltd, Cambridge, 2000

3. Rao, M. A., Rizvi, S. S. H., Datta, A. K., Engineering properties of foods, Taylor and Francis, Boca Raton, 2005

4. Rahman, M.S. Food Properties Handbook $2^{\text {nd }}$ Ed., CRC Press, Boca Raton, 2009 
5. Krokida, M.K.; Pangiotou, N.M.; Maroulis, Z.B.; Saravacos, G.D. Thermal conductivity: Literature data compilation for foodstuffs, International Journal of Food Properties, 2001, $4,111-137$.

6. Krokida, M. K., Michailidis, P. A., Maroulis, Z. B. and Saravacos, literature data of thermal conductivity of foodstuffs, International Journal of Food Properties, 2002, 5, 63111

7. Rask, C. Thermal properties of dough and bakery products: a review of published data. Journal of Food Engineering, 1989, 9, 167-193.

8. Carson, J. K., Measurement and modelling of thermal conductivity of sponge and yellow cakes as a function of porosity, International Journal of Food Properties, 17:1254-1263, 2014

9. Torquato S. Random heterogeneous materials. New York: Springer Verlag; 2002..

10. Hashin, Z. Shtrikman, S. A variational approach to the theory of the effective magnetic permeability of multiphase materials, Journal of Applied Physics, 1962, 33 3125-3131

11. Carson, J.K., Lovatt, S.J., Tanner, D.J., Cleland. A.C., Thermal conductivity bounds for isotropic, porous materials, International Journal of Heat and Mass Transfer, 2005, 48, $2150-2158$

12. Carson, J.K., Lovatt, S.J., Tanner, D.J., Cleland. A.C., Predicting the effective thermal conductivity of unfrozen, porous foods, Journal of Food Engineering, 2006, 75, 297-307.

13. Landauer, R. The Electrical Resistance of Binary Metallic Mixtures, Journal of Applied Physics, 1952, 23, 779-784

14. Kent, M., Christiansen, K., van Haneghem, I.A., Holtz, E., Morley, M.J., Nesvadba, P., Poulsen, K.P. Cost 90 collaborative measurements of thermal properties of foods, Journal of Food Engineering, 1984, 3, 117-150

15. User manual - TP08 Small Size Non-Steady-State Probe for Thermal Conductivity Measurement, Art no 5000-003 Version 0607, Hukseflux, www.hukseflux.com

16. Elustondo, D. Elustondo, M. P. Urbicain, M. J. New thermal conductivity probe design based on the analysis of error sources, Journal of Food Engineering, 2001,48, 325-333,. 
17. Ojha, T. P., Farrall, A. W., Dhanak, A. M., Stines, C. M. A method of determining heat transfer through powdered foods. Trans. ASAE, 1967, 10, 543-544.

18. MacCarthy, D. A. Effect of temperature and bulk density of spray-dried whole milk powder. Journal of Food Engineering, 1985, 4, 249-263

19. Chang, C.S.; Lai, F.S.; Miller, B.S. Thermal Conductivity and Specific Heat of Grain Dust. Trans. ASAE. 1980, 1303-1312.

20. Moysey, E.B.; Shaw, J.T.; Lampman, W.P. The Effect of Temperature and Moisture on the Thermal Properties of Rapeseed. Trans. ASAE. 1977, 768-771.

21. Wallapapan K., Sweat, V. E., Diehl, K. C., Engler, C. R., Thermal properties of porous foods, in: Okos, M.R. Physical and Chemical Properties of Food; American Society of Agricultural Engineers: 1986.

22. Carson, J.K., Wang, J.F., North, M.F., Cleland, D.J., Predicting the thermal conductivity of low water-content foods, Proceedings of the $23^{\text {rd }}$ IIR International Congress of Refrigeration, Prague, August 21- 26, 2011, Paper \# 407

23. Levy, F.L., A modified Maxwell-Eucken equation for calculating the thermal conductivity of two-component solutions or mixtures, International Journal of Refrigeration, 1981, 4, 223-225

24. Wang, J.F., Carson, J.K., North, M.F., Cleland, D.J., A new structural model of effective thermal conductivity for heterogeneous materials with co-continuous phases, International Journal of Heat and Mass Transfer, 2008, 51, 2389-2397 


\section{Figure and Table Captions}

Table 1: Protein, fat and carbohydrate compositions of the powdered foods (mass basis).

Table 2: Bulk densities, moisture contents and thermal conductivities of five powdered foods measured at $20^{\circ} \mathrm{C}$.

Table 3: Comparison of measured data against thermal conductivity bounds

Table 4: Comparison of measured data against thermal conductivity predictions

Figure 1: Thermal conductivity data for wheat flour along with thermal conductivity bounds

Figure 2: Thermal conductivity data for cocoa along with thermal conductivity bounds

Figure 3: Thermal conductivity data for sucrose along with thermal conductivity bounds 


\begin{tabular}{l|c|c|c} 
& \multicolumn{1}{c}{$\begin{array}{c}\text { Protein } \\
\%\end{array}$} & $\begin{array}{c}\text { Fat } \\
\%\end{array}$ & $\begin{array}{c}\text { Carbohydrate } \\
\%\end{array}$ \\
\hline Cocoa & 20 & 14 & 59 \\
Corn starch & - & - & 88 \\
Milk powder & 24 & 24 & 35 \\
Sucrose & - & - & 99 \\
Wheat flour & 12 & 2 & 72
\end{tabular}

Table 1: 
Bulk density Moisture content Thermal conductivity

\begin{tabular}{l|c|c|c}
\multicolumn{1}{c}{} & $\mathrm{kg} \mathrm{m}^{-3}$ & (mass fraction) & $\mathrm{W} \mathrm{m}^{-1} \mathrm{~K}^{-1}$ \\
\hline Cocoa & 405 & 0.0785 & 0.044 \\
Corn starch & 690 & 0.116 & 0.081 \\
Milk powder & 565 & 0.161 & 0.061 \\
Sucrose & 777 & 0.00920 & 0.085 \\
Wheat flour & 656 & 0.150 & 0.085
\end{tabular}

Table 2: 


\begin{tabular}{l|c|c|c|c|c|c|c} 
& \multirow{2}{*}{} & \multicolumn{6}{|c}{$k\left(\mathrm{Wm}^{-1} \mathrm{~K}^{-1}\right)$} \\
& $\varepsilon$ & Measured & Modelled \\
& & & (Eq. 1) & (Eq. 2) & (Eq. 3) & (Eq. 4) & (Eq. 5) \\
\hline Cocoa & 0.70 & 0.044 & 0.094 & 0.034 & 0.047 & 0.078 & 0.057 \\
Corn starch & 0.54 & 0.081 & 0.149 & 0.043 & 0.068 & 0.125 & 0.101 \\
Milk powder & 0.53 & 0.061 & 0.146 & 0.044 & 0.068 & 0.123 & 0.100 \\
Sucrose & 0.51 & 0.085 & 0.127 & 0.045 & 0.067 & 0.109 & 0.093 \\
Wheat flour & 0.54 & 0.085 & 0.155 & 0.044 & 0.068 & 0.130 & 0.104
\end{tabular}

Table 3 


\begin{tabular}{l|c|c|c|c|c|c|cc} 
& & \multicolumn{6}{|c|}{$k\left(\mathrm{Wm}^{-1} \mathrm{~K}^{-1}\right)$} & \multicolumn{3}{c}{$\xi$} \\
& $\varepsilon$ & Measured & Eq. (11) & Eq. (12) & Eq. (15) & Eq. (11) & Eq. (12) & Eq. (15) \\
\hline Cocoa & 0.70 & 0.044 & 0.0505 & 0.0585 & 0.0652 & 0.0061 & 0.0140 & 0.0208 \\
Corn starch & 0.54 & 0.081 & 0.0782 & 0.0918 & 0.0941 & 0.0029 & 0.0107 & 0.0131 \\
Milk powder & 0.53 & 0.061 & 0.0782 & 0.0914 & 0.0932 & 0.0173 & 0.0306 & 0.0324 \\
Sucrose & 0.51 & 0.085 & 0.0748 & 0.0860 & 0.0865 & 0.0102 & 0.0010 & 0.0015 \\
Wheat flour & 0.54 & 0.085 & 0.0799 & 0.0941 & 0.0965 & 0.0047 & 0.0095 & 0.0119 \\
\hline Average
\end{tabular}

Table 4 


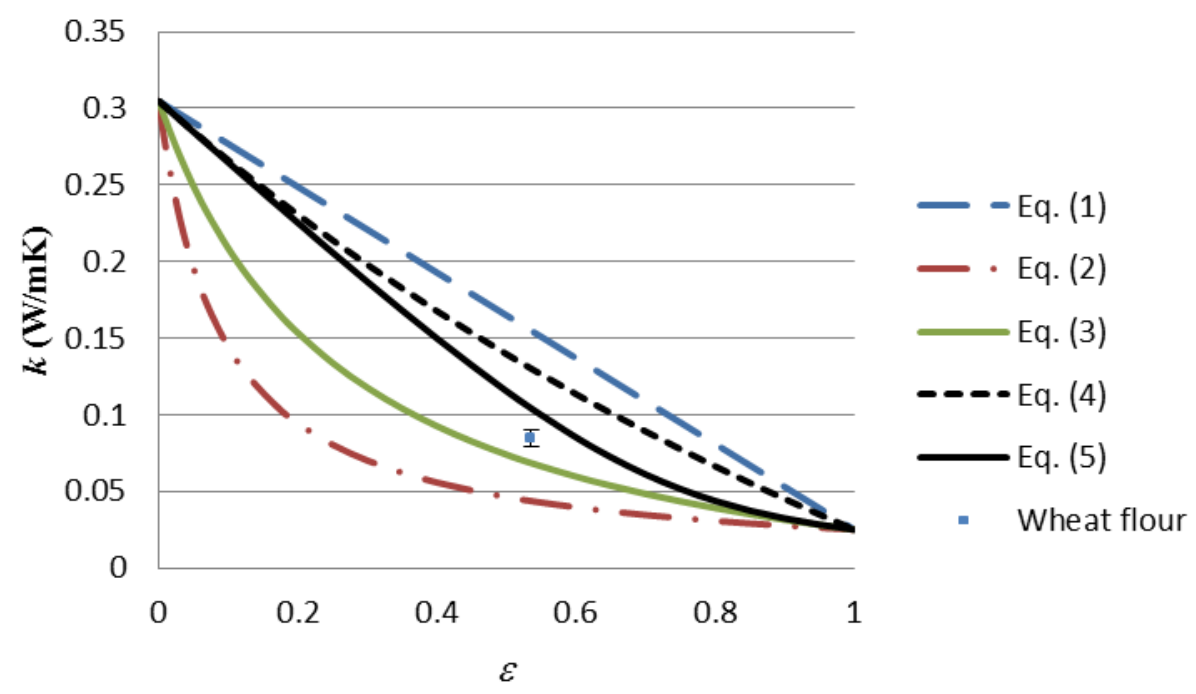

Figure 1 


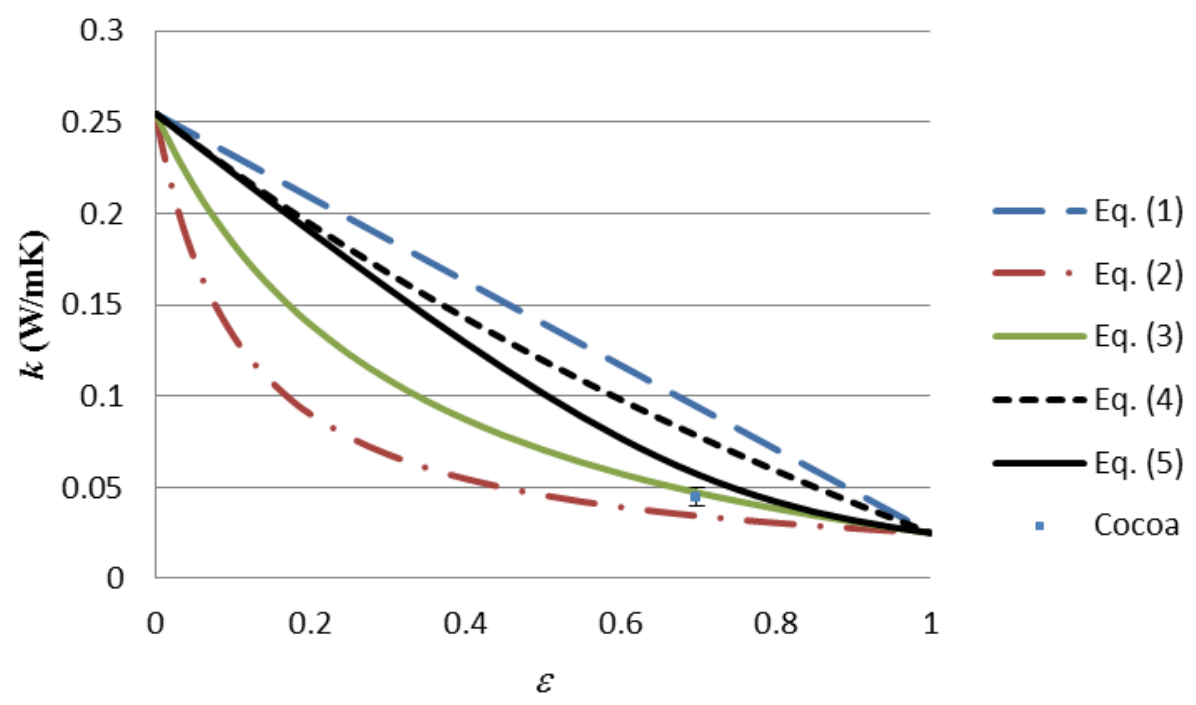

Figure 2: 


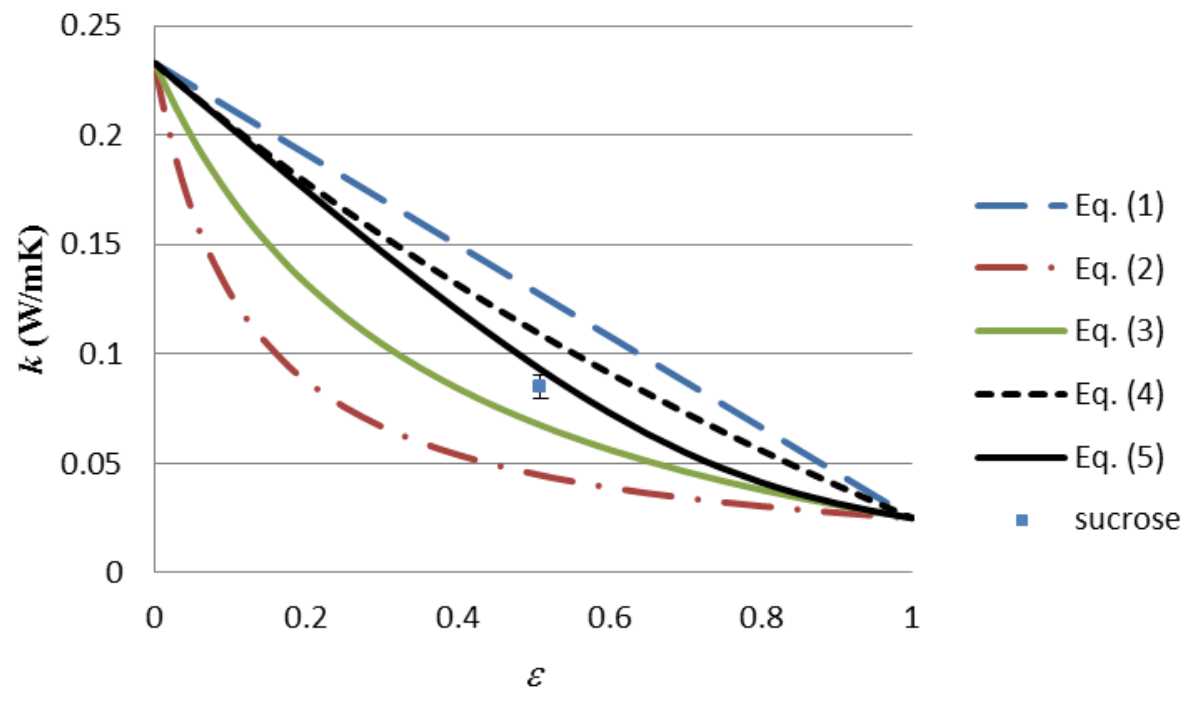

Figure 3 